\title{
Comparative use of longline oysterbeds and adjacent tidal flats by waterbirds
}

\author{
LINDA M. CONNOLLY and MARK A. COLWELL
}

\section{Summary}

Commercial oyster Crassostrea spp. cultivation in intertidal habitats may degrade foraging habitat of waterbirds. Consequently, we compared species abundances, community similarity and diversity of waterbirds using longline oyster culture beds and adjacent control plots on tidal flats of Humboldt Bay, California. Abundances of most species differed significantly between treatments, with seven of 13 shorebirds Charadriiformes and three of four wading birds Ciconiiformes more abundant on longline plots. By contrast, Black-bellied Plover Pluvialis squatarola were more abundant on control plots. Marbled Godwit Limosa fedoa, Long-billed Curlew Numenius americanus and Dunlin Calidris alpina showed mixed results depending on location and Great Blue Heron Ardea herodias were more abundant only on one control plot. Community composition was similar on longline and control plots, although diversity $\left(H^{\prime}\right)$ was greater on longline plots. Varying species' responses to longline techniques may have been associated with interspecific differences in diet and foraging behaviour, and the impacts of longlines and oyster-harvesting on prey distribution. Overall, longlines did not negatively affect the foraging behaviour of most species, but the underlying causes for increased bird use may lead to impacts on other trophic levels and over a longer temporal scale.

\section{Introduction}

Tidelands provide critical foraging habitat for waterbirds, especially during winter and migration periods. Oyster Crassostrea spp. culture is a prevalent human use of coastal bays (Burrell 1985), and has the potential to alter intertidal feeding habitats of waterbirds. Habitat alteration can occur directly by increased sedimentation or indirectly through increased human activity associated with cultivation. The techniques of oyster cultivation can be classified as those occurring directly on the surface sediments (hereafter termed "bottom culture") and those suspending oysters above substrates (hereafter termed "off-bottom"). Bottom culture, the traditional method, involves spreading fragments of oyster shell seeded with young, growing oysters directly onto the substrate and harvesting by dredge after 3-5 years (Simenstad and Fresh 1995). Dredge-harvesting of bottom-culture plots resuspends fine sediments and uproots eelgrass Zostera marina (Waddell 1964), resulting in lowered eelgrass densities, altered current flow, and increased sedimentation and erosion (e.g. Everett et al. 1995). As of 1987, at least $90 \%$ of U.S. Pacific coast oysters were grown by this method (Chew 1987). Soft sediments cause oysters to sink and suffocate, so growers have tended to cultivate tidelands that have firm substrates (Chew 1987); however, because off-bottom methods suspend oysters, cultivation can be expanded into intertidal areas of softer substrate (Chew 1987, Simenstad and Fresh 1995). One such offbottom method is longline culture, where seeded shell is grown on ropes at $15-30 \mathrm{~cm}$ 
intervals and suspended off the bottom by rows of plastic pipes (Chew 1987, Simenstad and Fresh 1995).

The altered habitat conditions associated with oyster culture have the potential to influence invertebrate prey densities (Yates et al. 1993) and behaviours of foraging shorebirds (Myers et al. 1980, Quammen 1982, Grant 1984). However, it is not well understood how oyster cultivation affects bird use of intertidal areas. Research at Tomales Bay, California, showed shorebirds were less abundant on off-bottom oyster plots, although species varied in response (Kelly et al. 1996). Because some methods of cultivation result in the development of previously uncultured areas (Chew 1987), further investigations are necessary to determine how certain practices affect waterbirds.

We investigated waterbird use of longline oysterbeds on Humboldt Bay, California, designated as an International site in the Western Hemisphere Shorebird Reserve Network (Harrington and Perry 1995). Of the 4,000-4,500 ha of mudflat exposed at low tide, oyster growers own or lease 1,650 ha of tideland and cultivate Pacific oysters C. gigas on about 260 ha at any given time (U.S. Army Corps of Engineers 1997). Oysters are typically grown at tidal elevations less than $1 \mathrm{~m}$ above mean lower low water (MLLW) (Simenstad and Fresh 1995), thus overlapping with the distribution of eelgrass, which occurs mainly below about 0.3 m MLLW (Keller and Harris 1966). Eelgrass grows on about $20 \%$ of Humboldt Bay's intertidal mudflats (Barnhart et al. 1992), and provides food for Brant Branta bernicla and Wigeon Anas americana (Reed et al. 1998), as well as habitat for fishes and invertebrates, including commercially important herring Clupea pallasi and Dungeness crab Cancer magister (Barnhart et al. 1992). In 1997, the principal oyster cultivator on the bay initiated removal of $70 \%$ of their 200 ha of bottom-culture areas to reduce impacts to eelgrass, and simultaneously began developing areas for longline culture (Coast Seafoods Company 1997). Concerns that these efforts to conserve eelgrass may compromise tidal flats and their biota prompted our study. Our aims were to compare bird abundance, diversity, and composition on longline oyster plots with those on adjacent tidal flats. Additionally, we examined habitat correlates of substrates to explain differences between longline and control plots.

\section{Methods}

We selected five longline plots on Humboldt Bay, representing several locations and microhabitats: Arcata Channel, Bird Island, North Indian Island, South Indian Island, and Mad River Slough (Figure 1). We paired each longline plot with an adjacent control (tidal flat) plot similar in area, shape, substrate, micro-channelization and elevation; hereafter these paired plots are referred to as treatments. Control plots had a similar oyster-culture history to the paired longline plots (Moore 2001a). Longline plots consisted of oyster longlines suspended from plastic pipes inserted vertically into the substrate (Figure 2). Longlines were usually spaced into rows $70 \mathrm{~cm}$ wide, although at three sites (Arcata Channel, South Indian Island and Mad River Slough), every fifth row was $1.5 \mathrm{~m}$ in width. We designated these as "narrow" and "wide" rows, respectively. A $2 \mathrm{~m}$ gap separated every $30-36 \mathrm{~m}$ of longline length, creating aisles perpendicular to the longline rows (Figure 3). We chose plots with rows oriented perpendicular to channels to facilitate observation of birds (see below). 


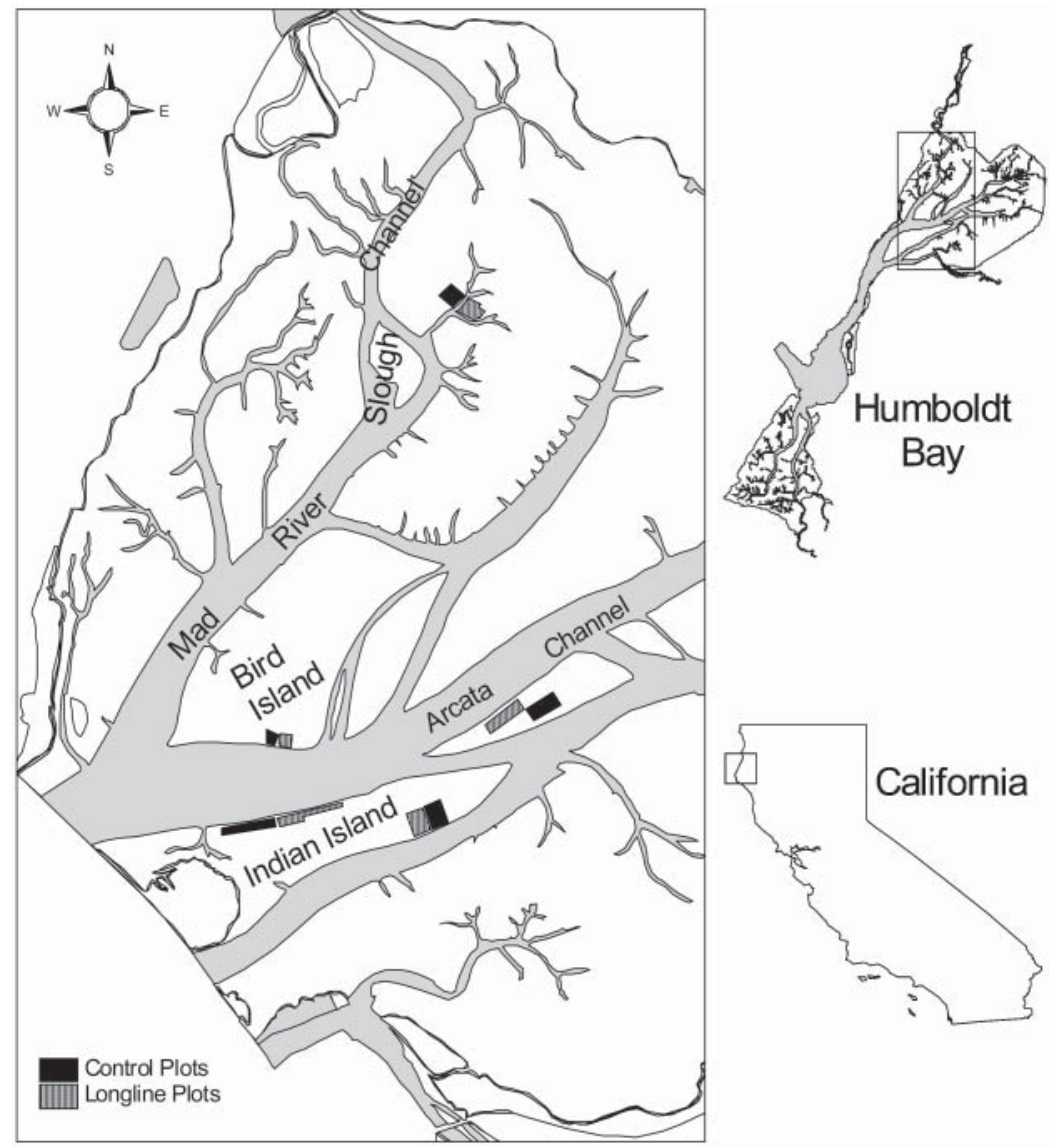

$\begin{array}{lllllll}500 & 0 & 500 & 1000 & 1500 & 2000 & 2500\end{array}$ Meters

Figure 1. Locations of longline and control plots on Humboldt Bay, California.

Before (May 1999) and after (June 2000) conducting bird observations, we used a stratified random method to sample habitats on longline and control plots. We divided each plot into a grid of 15 or 16 equal-sized units ( 3 by 5 or 4 by 4 ), randomly selected units, and then sampled one random location per unit. In May 1999, we sampled 13 units on all plots except Bird Island, where we sampled only 6 units because of its smaller size. In June 2000, we selected 15 units per larger plot and 10 units on the smaller Bird Island plots.

At each sample site, we used a $65 \times 65 \mathrm{~cm}$ sampling frame to visually estimate percentage cover of oyster shell and eelgrass. At five locations along the base of the frame, we probed a $4 \mathrm{~mm}$ diameter $\operatorname{rod} 15 \mathrm{~cm}$ into the substrate to measure depth and frequency with which the probe encountered resistance from a subsurface object. Within the sampling frame, we selected locations at random to measure penetrability and collect a core sample (May 1999 only). The device we used to gauge penetrability 


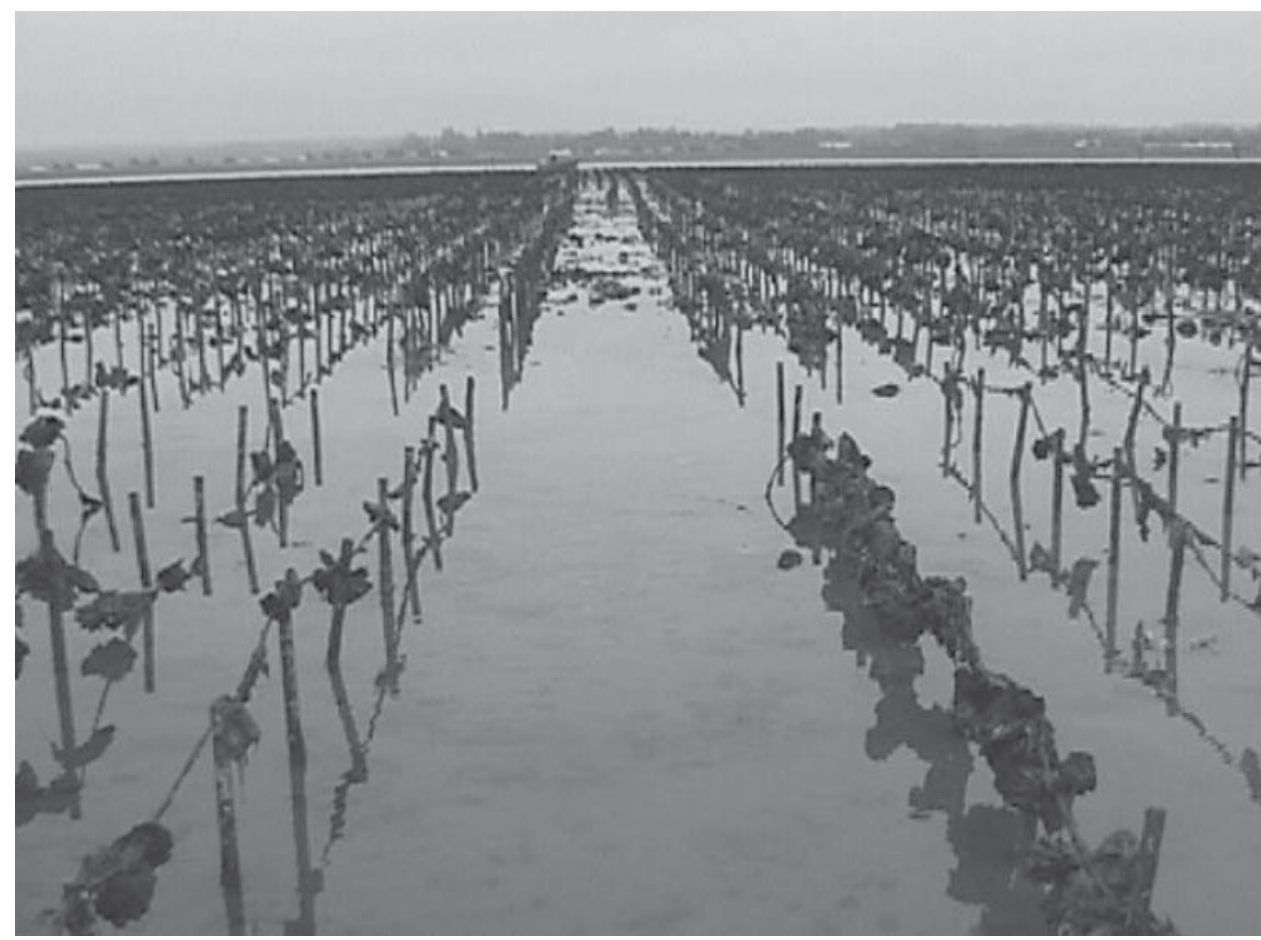

Figure 2. Longlines at South Indian Island, Humboldt Bay, California. Oysters were suspended from ropes strung along plastic pipes.

consisted of a $336 \mathrm{~g}$ lead weight dropped from a height of $58 \mathrm{~cm}$ onto a wooden dowel along a $4 \mathrm{~mm}$ diameter rod (Colwell and Dodd 1995). We used a $10.3 \mathrm{~cm}$ diameter core sampler pushed to a depth of $10 \mathrm{~cm}$ to sample subsurface debris. In the laboratory, we removed oyster-shell fragments from each core sample with a $5 \mathrm{~mm}$ sieve, and then dried and weighed the shell. We compared (longline vs control plot) eelgrass and shell cover, penetrability, frequency of hitting an object with the probe, average probe depth and shell mass using a two-sample $t$-test or a Mann-Whitney $U$-test for non-normal data.

\section{Bird surveys}

We conducted paired surveys (longline and adjacent control plots) of birds on 129 days between I June 1999 and 31 May 2000, when predicted low tides <0.3 m MLLW exposed most plots. Using $10 \times 42$ binoculars, we surveyed birds from a boat moving slowly, perpendicular to longlines. Because fog sometimes compromised identification of similar species, we treated three taxa as species for purposes of analysis: peeps (Least Sandpipers Calidris minutilla and Western Sandpipers C. mauri); yellowlegs (Greater Yellowlegs Tringa melanoleuca and Lesser Yellowlegs T. flavipes) and dowitchers (Short-billed Dowitchers Limnodromus griseus and Long-billed Dowitchers L. scolopaceus). For each bird observed, we recorded the species and whether it was in a narrow row, wide row or aisle, to determine whether birds used longline spaces of different widths according to their availability. 
a) All narrow rows

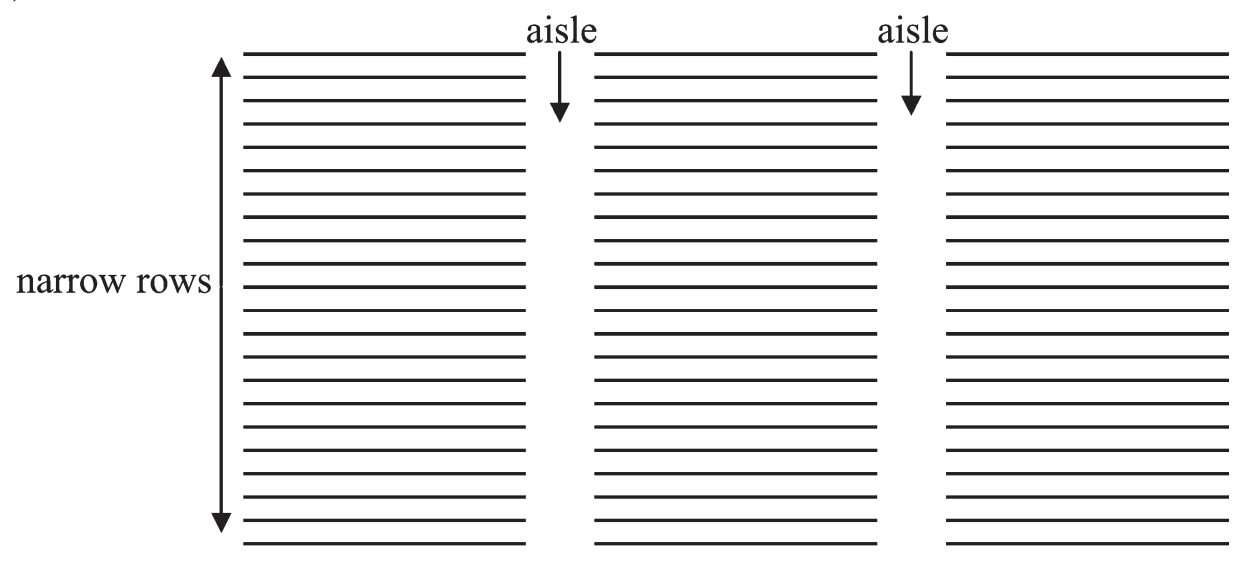

b) Narrow rows with wide rows

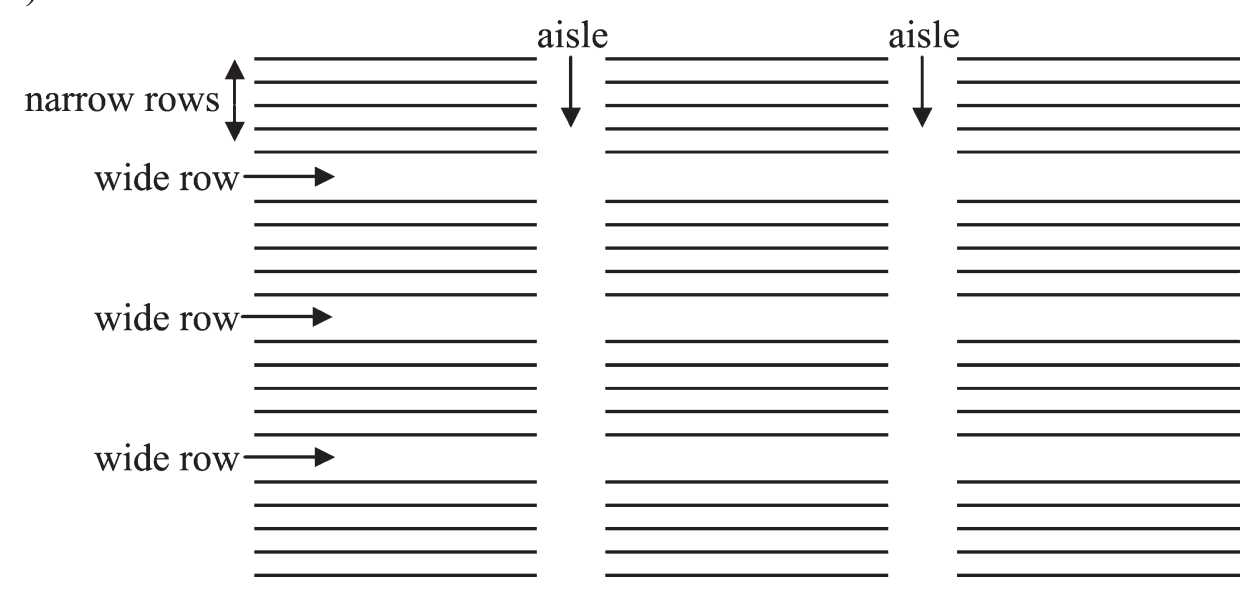

Figure 3. Layout of longline plots comprising $(a)$ only narrow rows or $(b)$ narrow rows interspersed with wide rows.

We surveyed a location only when longline and paired control plots could be viewed under similar flooding conditions (i.e. exposed tidal flat, $1-10 \mathrm{~cm}$ water, or $>10 \mathrm{~cm}$ water). We did not survey plots with greater than $45 \mathrm{~cm}$ of flooding (when we could no longer see longlines), because birds generally could not use plots under those conditions. Because the five locations differed in elevation, we began the survey route approximately $1.5 \mathrm{~h}$ before low tide at the highest elevation plot, and finished around low tide at the lowest elevation plot; as a result the order in which we surveyed plots was consistent and predetermined by tide. On days when (neap) low tides flooded low-elevation plots, we began surveys $\mathrm{I}$ h prior to low tide and did not survey flooded plots.

For each species, we compared abundance between treatments using a Wilcoxon matched-pairs signed-rank test, pairing data for each day. We analysed the five locations separately because of differences in habitat (e.g. elevation and substrate 
differences) and location (e.g. proximity to roosts or alternative feeding habitats), as well as different numbers of surveys (Appendix). We used stepwise multiple regressions to examine relationships between abundance (standardized as the total observations of a species divided by number of observation days a plot was exposed and hence available to foraging birds) of each species and habitat measurements (average values recorded before and after bird observations). We included a coded variable (longline $=1$, control $=0$ ) to examine treatment effects. For each species, we based plot availability on water depth, as most shorebirds do not forage in water that is greater than "knee"-depth (Evans 1979). We analysed only species that used a minimum of three (of 10) plots. We transformed $\left(\log _{10}+1\right)$ non-normal data. To compare community composition between paired plots, we computed Jaccard's index of similarity, using the sum of species present over the year. This index describes the degree to which species are present on both a longline plot and its paired control plot by assigning a value between $\mathrm{O}$ and $\mathrm{I}$, with $\mathrm{o}$ representing no species in common, and $I$ indicating all species in common. We used the Shannon-Weiner $\left(H^{\prime}\right)$ index to gauge species diversity and compared $H^{\prime}$ values using a paired $t$-test (of longline and control plots). We used a Goodness-of-Fit test with Yates' continuity correction to assess whether species (when $n>1$ ) used narrow versus wide rows (including aisles) in proportion to availability (area).

\section{Results}

\section{Habitat characteristics}

With few exceptions, habitat on plots at the start and end of the study was similar (Table 1). When differences existed they involved increased shell cover and decreased eelgrass cover on longline plots, perhaps because four of five of these sites had unscheduled oyster harvest during the study. Overall, treatments were similar in habitat, but control plots tended to have lower shell cover, lower shell mass, lower frequency of subsurface hits by correspondingly deeper probes, higher eelgrass cover and lower penetrability than longline plots.

\section{Waterbird use}

We observed 17 species of waterbird on the five study sites, resulting in 85 possible pair-wise comparisons between treatments. Because species never occurred on either treatment in 17 cases, 68 comparisons resulted. Species varied greatly in use of longline and control plots (Table 2, Appendix). In most cases where significant differences existed between treatments, species were more likely to occur on longline plots. However, two species (Black-bellied Plover Pluvialis squatarola and Great Blue Heron Ardea herodius) were more commonly encountered on control plots. Lastly, three species varied in response to treatments, depending on location.

The varied species' responses to treatments yielded few consistent differences in community patterns between longline and control plots (Table 3). Diversity was greater on longline plots compared with controls (Paired $t$-test, $t_{8}=4.16, P=0.014$ ), which was surprising given that there were small differences in number of species and substantial variation in total observations. Longline and control plots shared $50-92 \%$ of species, depending on location. Low similarities resulted from the absence of wading birds from control plots at two sites. 


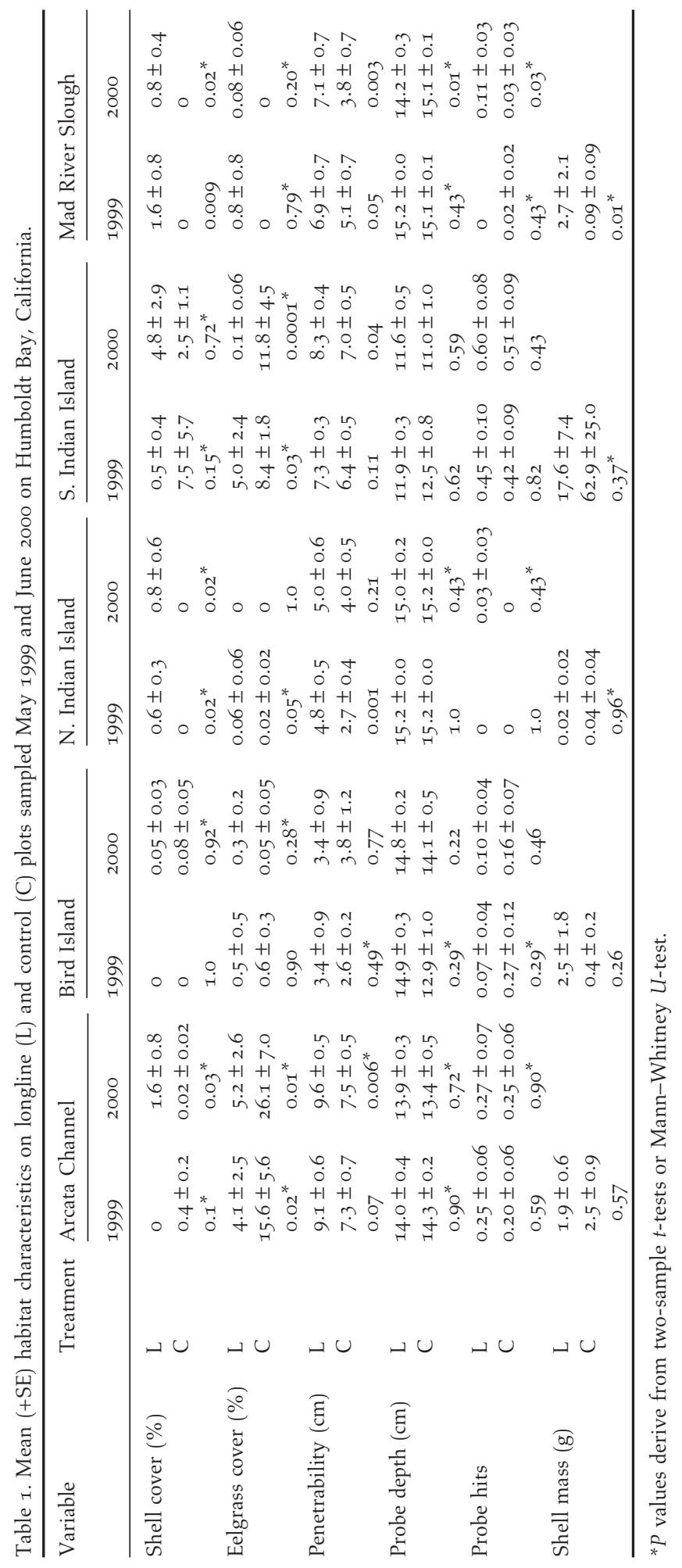




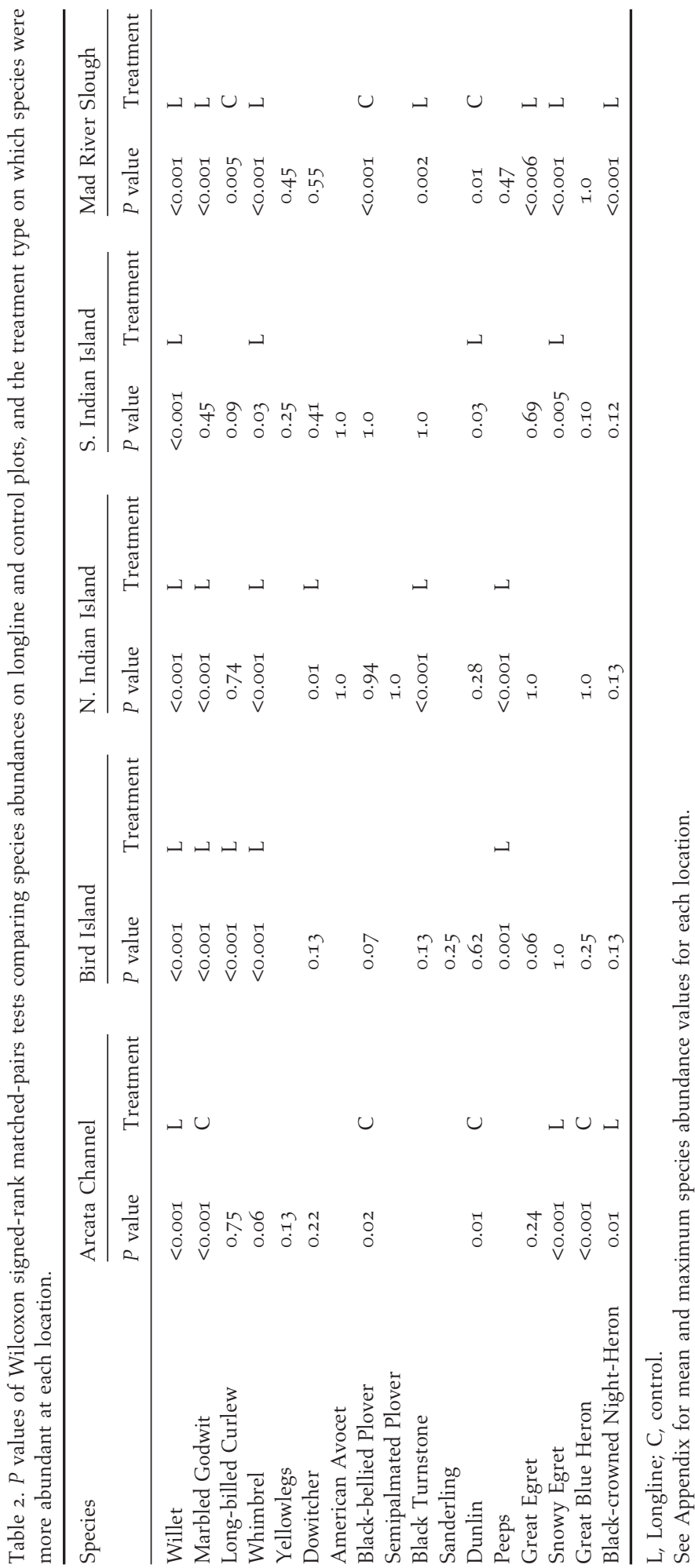




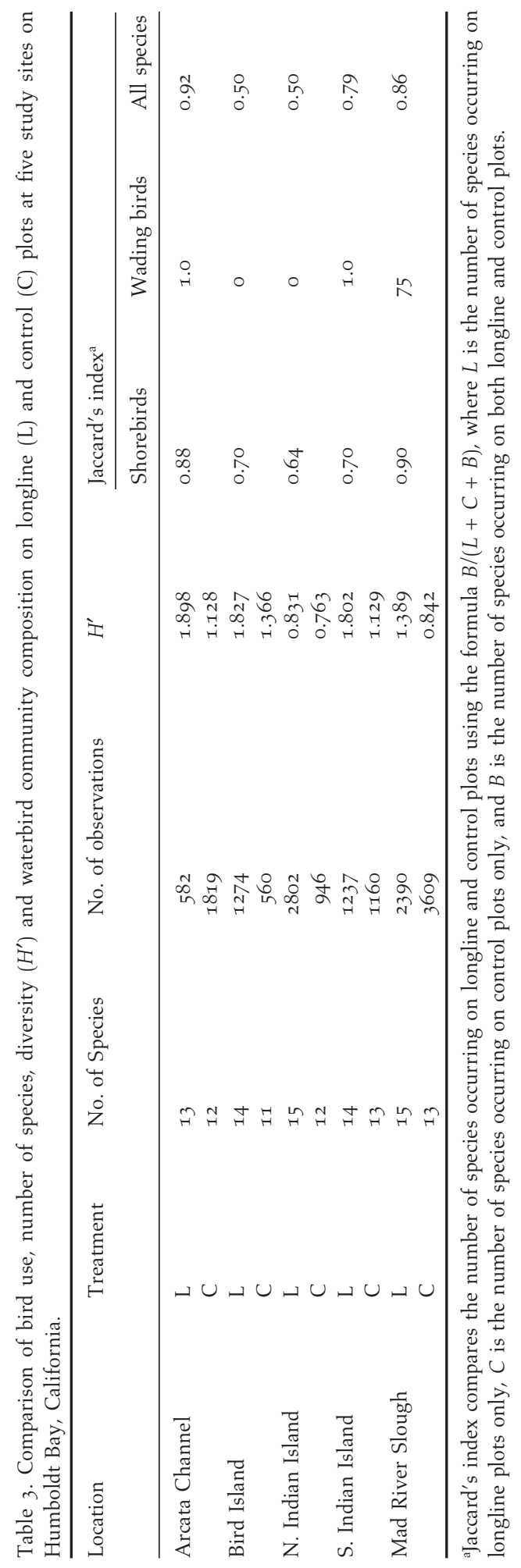




\section{Bird-habitat relationships}

Four species exhibited significant relationships between abundance and habitat characteristics (Table 4). Marbled Godwits Limosa fedoa were more abundant on plots with higher eelgrass cover and lower probe depth. Dowitcher abundance correlated positively with eelgrass cover. Black Turnstones Arenaria melanocephala were more abundant on longline plots, and under conditions of lower penetrability and greater eelgrass cover. Peeps were more abundant on plots with less subsurface debris.

\section{Wide versus narrow rows}

In 15 of 60 comparisons, bird use of wide areas exceeded availability (Table 5). Strongest preference for wide rows was among larger species, including half of all wading bird comparisons, together with Marbled Godwit, Long-billed Curlew Numenius americanus, dowitchers, Black Turnstone and Dunlin Calidris alpina. The pattern of greater-than-expected use of wide rows occurred at four locations, the exception being North Indian Island where Whimbrels Numenius phaeopus and peeps used narrow rows disproportionately (Table 4 ). This narrow, rectangular longline plot covered a long stretch of shoreline, and it had at least $50 \%$ of continuous length with no wide rows or aisles. Moreover, the North Indian Island plots covered such a great length of shoreline that the elevation difference across longline and control plots exceeded that of any other location. The proportion of a plot consisting of narrow or wide areas did not influence bird use of those areas. Plots where birds used wide areas disproportionately higher than availability ranged from $2.2 \%$ to $41.6 \%$ wide areas, but North Indian Island was $3.8 \%$ wide area and yielded results favouring the use of narrow areas.

\section{Discussion}

Shorebird use of longline plots varied among species. Where statistical differences were found, five species (Willet Catoptrophorus semipalmatus, Whimbrel, dowitchers, peeps and Black Turnstone) were always more abundant on longline plots than control plots, one species (Black-bellied Plover) was more abundant only on control plots, and three (Long-billed Curlew, Marbled Godwit and Dunlin) used longline or control plots differently depending on location. Species that exhibited no clear pattern of longline and control plot use were infrequently observed, thus small sample sizes (either number of days present or total number of birds) probably influenced results. Variation in use of longlines was not clearly defined by taxonomy, but presumably reflected the behaviour and habitat associations of different species.

Greater bird abundances on longline plots suggest that some species may have responded to an increased foraging opportunity, either by focusing on increased prey density or by exploiting greater prey diversity. Shorebird densities are commonly correlated with the densities of their principal prey (Goss-Custard et al. 1977, Bryant 1979, Pienkowski 1982, Meire and Kuyken 1984), so densities of foraging shorebirds should be higher where main prey abundances are higher. Conversely, shorebirds may diversify their diet to compensate for low densities of their main prey (Hicklin and Smith 1984).

Shellfish beds create habitat for benthic fauna by providing cover and nutrients (e.g. Kaspar et al. 1985, Dankers and Zuidema 1995). Oysters and shell fragments 


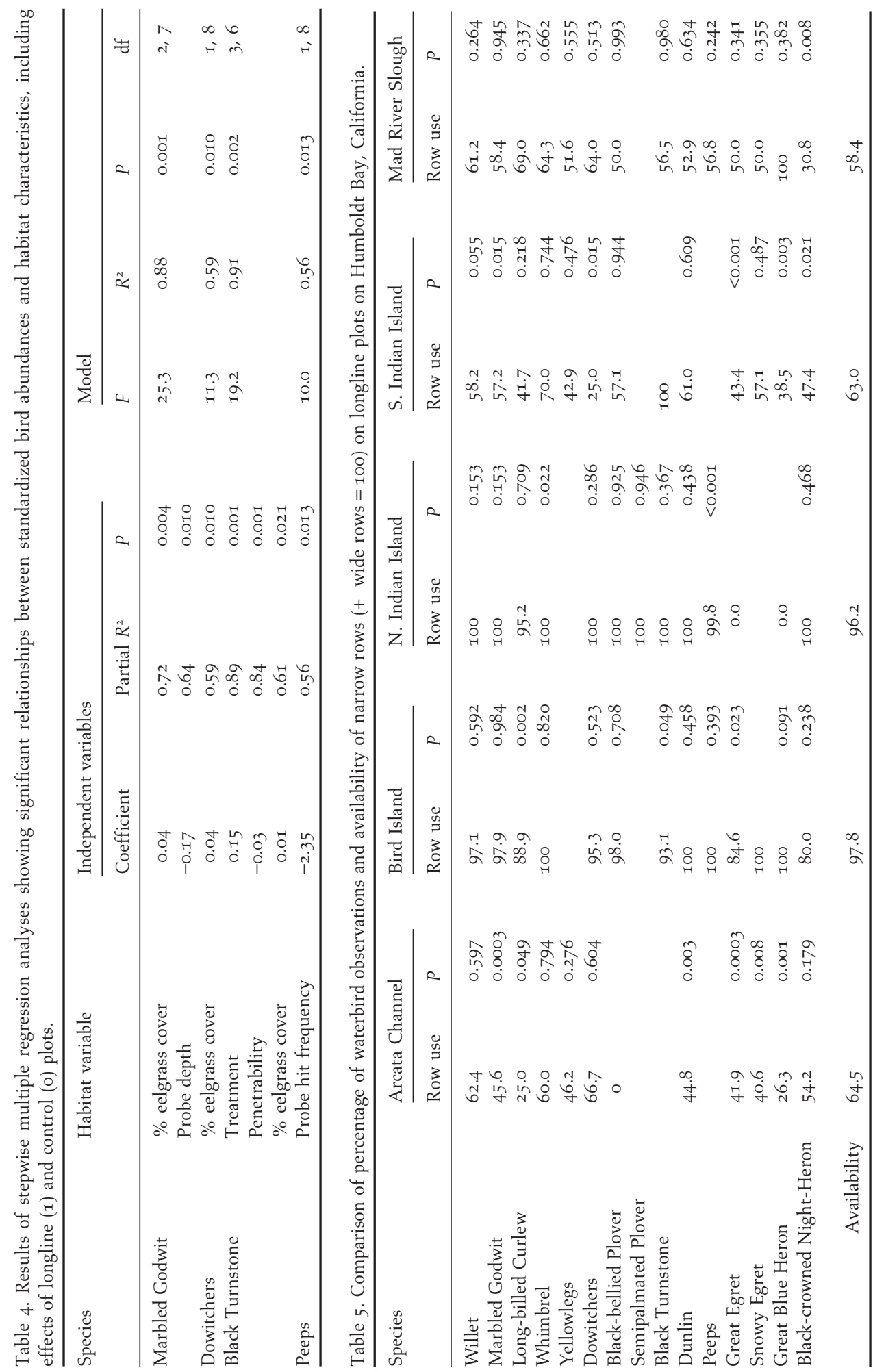


falling from longlines probably accounted for greater surface and subsurface debris measured at some longline plots. Shells on lines and on the ground may therefore have enabled higher invertebrate densities and improved foraging opportunities for some shorebirds.

In addition to potentially higher prey densities, increased prey availability may result from unique microtopography characteristics on oysterbeds. Substrate wetness enhances penetrability, which may increase prey availability (Myers et al. 1980, Connors et al. 1981, Kelsey and Hassall 1989), because burrowing invertebrates remain near the water level as the surface dries (Grant 1984, Puttick 1984). Microtopography on longline plots included footprint depressions of oyster workers and scoured areas, sometimes holding water, around support pipes and oysters.

Shellfish culture areas may also experience greater overall invertebrate diversity, with invasions of new species at the expense of natives (Mattson and Linden 1983). For example, localized mudflat trampling by oyster workers may mimic natural bioturbation, resulting in altered invertebrate communities within trampled patches and increased total diversity over a greater area (Raffaelli and Milne 1987, Cadee 1990, Hall et al. 1991). Additionally, longlines probably trapped floating algae and provided structures for anchorage (Everett et al. 1995): Ulva and Porphyra were attached only to support pipes on longline plots, and Enteromorpha was tangled in longlines at Bird Island but absent from the control plot. These algal mats support more abundant but different invertebrate assemblages compared with bare mudflats (Perkins and Abbott 1972, Soulsby et al. 1982, Norkko et al. 2000).

Willet and Whimbrel abundances were especially higher on longline plots. Additionally, apart from two individuals, Whimbrels used longline plots exclusively. Because both species employ a variety of foraging techniques (Velasquez and Navarro 1993, Turpie and Hockey 1997) and have widely varied diets (Stenzel et al. 1976, Velasquez and Navarro 1993), they are able to feed in many habitat types, including areas with bottom culture of oysters (Moore 2001b). Consistently greater use of longline plots suggests that Willets and Whimbrels benefited most from either more abundant or more diverse prey resources that longlines offered.

When differences existed, dowitchers, peeps and Black Turnstones were more abundant only on longline plots. Dowitchers and peeps peck and probe the substrate for prey (Grant 1984, Colwell and Landrum 1993), and therefore may have been less able than Willets or Whimbrels to exploit a potentially more diverse prey base. Black Turnstones were more abundant on longline plots at only two of four locations, but they used longline plots almost exclusively. Turnstones typically frequent rocky coasts, where they forage by flipping over stones and algae and pecking at prey (Hayman et al. 1986). In this study, Black Turnstones were sometimes observed pecking directly at oyster lines or at oysters on the ground. The presence and behaviour of turnstones, coupled with the positive correlation between turnstone abundance and firmer substrates, suggest that longline plots had characteristics of a different habitat from relatively unaltered tidal flats.

Several explanations could account for greater use and increased foraging on control plots by Black-bellied Plovers. First, plovers use visual cues to detect prey (Pienkowski 1983, Turpie and Hockey 1997), and their stereotyped run-stop-peck method of prey capture is associated with a specialized diet (polychaete worms: Baker 1974). Thus, if longline plots had altered prey communities, plovers probably did not respond by 
diversifying their feeding habits. Second, because obscured visual cues decrease efficiency of prey capture by visual feeders (Dann 1991, Shepherd and Boates 1999), the structural habitat complexity of longlines may have rendered plovers less able to detect and capture prey. Finally, territoriality caused by mutual avoidance of nonbreeding Black-bellied Plovers (Stinson 1977, Townshend et al. 1984, Turpie 1995) may have resulted in foraging interference. Behavioural responses of surface invertebrates (Goss-Custard 1970, Backwell et al. 1998) result from high densities of visual foragers (Goss-Custard 1984). Thus, visual feeders experience lower feeding success than tactile foragers in the presence of other birds (Goss-Custard 1976, Goss-Custard 1980, Selman and Goss-Custard 1988). Significantly greater numbers of Black-bellied Plover on control plots in two of five cases may indicate one or more of the following: (I) greater total numbers of shorebirds on longline plots interfered with plover foraging by making prey less available, (2) plovers were less able to detect otherwise available prey because of visual obstructions, or (3) the principal prey of plovers occurred in higher density on control plots.

American Avocet Recurvirostra americana abundance was not high enough to yield statistically significant results, but their exclusive use of control plots may reflect specific habitat requirements dictated by morphology. Because avocets forage on wet tidal flats by pecking or scything the long, recurved bill sideways through the mud for prey, reduced foraging success and fewer scythes (more pecks at the surface) result from increased sediment particle size (Quammen 1982). Longline structures, fallen oysters and shell fragments may similarly impede the sweeping motion of avocets by blocking areas at or beneath the surface.

The use of longline and control plots by Long-billed Curlew, Marbled Godwit and Dunlin varied across locations. At Humboldt Bay, some Long-billed Curlews defend feeding territories during the non-breeding season (Colwell and Mathis 2001). Relatively low densities of curlews on most study plots suggest that territories may be uniformly distributed at the spatial scale of this study (Mathis et al. in review). Habitat use may thus be difficult to discern if only one or two curlew territories overlap a longline or control plot.

Marbled Godwit use varied with location elevation. Godwits were more abundant on longline than control plots at the three highest elevations. However, because godwit abundance was positively correlated with eelgrass cover, and control plots of low elevations had greater eelgrass cover than longline plots, godwits were more abundant on control than longline plots at lower elevations. Godwit and other species (dowitchers, Black Turnstone) whose abundances increased with eelgrass cover may have responded to high abundance (Homziak et al. 1982, Heck et al. 1989), diversity (Stoner 1980), richness (Lewis and Stoner 1983, Heck et al. 1995) or availability (reduced desiccation: Kalejta and Hockey 1991) of prey in eelgrass beds. It is unknown whether longlines influence eelgrass patterns because historical distributions of eelgrass on Humboldt Bay are not well documented, and bottom culture of oysters over 50 years may have influenced eelgrass growth and density prior to longline implementation (e.g. Waddell 1964). The unexpected negative relationship between godwit abundance and measured probe depth might be spurious or could indicate that godwits frequently pecked prey from eelgrass rather than probing the substrate.

Dunlin use of longline and control plots did not vary according to any measured habitat variable. Dunlins forage using visual and tactile cues; they peck and shallowly probe to detect prey (Kelsey and Hassall 1989). Thus, greater numbers at two control 
plots and one longline plot obscure the relationship between Dunlin foraging behaviour and plot use.

\section{Predator avoidance}

Kelly et al. (1996) suggested that off-bottom structures could conceal shorebirds from raptors, but selection of longline sites for protection should not be expected from shorebirds, which typically do not seek cover to avoid predation (Metcalfe 1984a). Shorebirds in flocks share vigilance with neighbours they can see (Metcalfe 1984b), but birds foraging on structurally complex longline plots may spend more time being vigilant and thus benefit less from feeding in flocks (Stinson 1980, Metcalfe 1984a). Within longline plots, greater proportional use of wide rows than narrow rows by some species may be a strategy to exploit the prey base while experiencing greater overhead visibility.

\section{Wading birds}

All wading birds except Great Blue Heron were more abundant on longline plots than on control plots, when differences existed. Alterations to mudflats by longlines may have produced favourable foraging conditions by enhancing invertebrate density at the surface, as described above, or by trapping small fish in pools formed via erosion or trampling. For example, at two locations that were never flooded during observations, waders were absent from control plots but foraged on longline plots, suggesting that they fed on prey made available directly or indirectly by the presence of longlines. Black-crowned Night-Heron Nycticorax nycticorax occasionally perched on longlines during higher tide levels, perhaps to continue fishing (Godin 1977). Oysters themselves probably contribute to the diets of waders. We observed one Great Egret Ardea alba pecking at an oyster, and we were told by oyster workers that egrets can consume a substantial proportion of young that are left on tidal flats in mesh bags to mature prior to "planting" in longlines.

Within longline plots, waders frequently used wide rows proportionately more than narrow rows. Wide rows may possess features of both longline and control plots: altered prey base with open space for greater visibility. Birds may benefit by detecting prey with fewer visual obstructions and by increased vigilance.

\section{Conclusions}

Differential species use of study plots on Humboldt Bay implies that longline oyster culture altered mudflat habitats and prey populations. Overall, birds did not appear to avoid longline areas compared with adjacent tidal flats. Rather, many species were more abundant and diversity was greater on longline plots. Any benefits of longlines, however, may be temporary, as mature oysters and lines are removed every 2-3 years and replaced with bare shells (Griffin 1997), and plots are periodically rotated out of culture (Coast Seafoods Company 1997). Further, temporary benefits to birds may be compromised by long-term habitat impacts, such as increased sedimentation or loss of native mudflat fauna (Kaspar et al. 1985) via competition with exotic species.

Given the relatively recent origins of longline oyster culture on Humboldt Bay, future study should examine the succession of changes in sediment and vegetative 


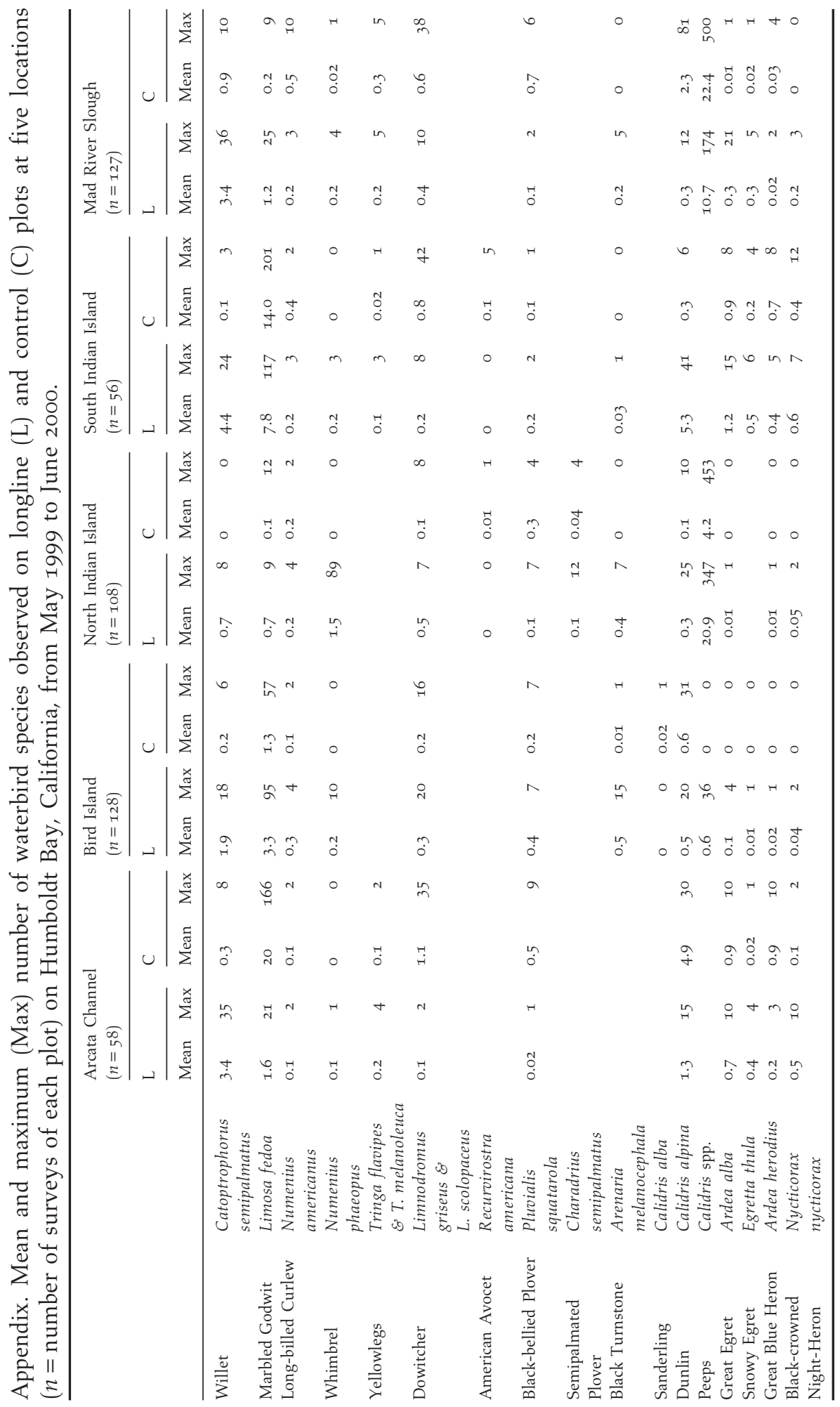


qualities of longline plots and the effects these have on invertebrates and their avian predators. Foraging of birds could be further studied to address whether individuals use similar foraging techniques, feed on the same prey, or have similar intake rates in longline areas as on mudflats. The process of rotating plots out of culture should be studied to determine whether altered populations (e.g. invertebrates, eelgrass) return to original distributions when longlines are removed.

\section{Acknowledgements}

We thank J. Moore and J. S. Yeager for aiding in data collection. Coast Seafoods Company provided access, transportation and valuable information regarding oyster culture. Additional assistance was provided by T. L. George, F. Weckerly and R. Mathis. We thank J. Sloan and J. Moore for reviewing the manuscript. Financial support for our work was provided by the Coast Seafoods Company and the Office of Research and Graduate Studies at Humboldt State University.

\section{References}

Backwell, P. R. Y., O'Hara, P. D. and Christy, J. H. (1998) Prey availability and selective foraging in shorebirds. Anim. Behav. 55: 1659-1667.

Baker, M. C. (1974) Foraging behavior of Black-bellied Plovers (Pluvialis squatarola). Ecology 55: 162-167.

Barnhart, R. A., Boyd, M. J. and Pequegnat, J. E. (1992) The ecology of Humboldt Bay, California: an estuarine profile. Washington, DC: U.S. Fish and Wildlife Service (Biological Report 1).

Bryant, D. M. (1979) Effects of prey density and site character on estuary usage by overwintering waders (Charadrii). Estuar. Coast. Mar. Sci. 9: 369-384.

Burger, J. (1981) The effect of human activity on birds at a coastal bay. Biol. Conserv. 21: 231-241.

Burrell, V. B. (1985) Oyster culture. Pp. 235-274 in J. V. Huner and E. E. Brown, eds. Crustacean and mollusk aquaculture in the United States. Westport, CN: AVI Publishing.

Cadee, G. C. (1990) Feeding traces and bioturbation by birds on a tidal flat, Dutch Wadden Sea. Ichnos 1: 23-30.

Chew, K. K. (1987) Oyster aquaculture in the Pacific Northwest. Pp. 67-76 in S. Keller, ed. Proceedings of the fourth Alaska aquaculture conference. Fairbanks, AK: Alaska Sea Grant College Program.

Coast Seafoods Company. (1997) First draft management plan for Coast Seafoods Company commercial shellfishing in Humboldt Bay, California, July 10, 1997.

Colwell, M. A. and Dodd, S. L. (1995) Waterbird communities and habitat relationships in coastal pastures of northern California. Conserv. Biol. 9: 827-834.

Colwell, M. A. and Landrum, S. L. (1993) Nonrandom shorebird distribution and fine-scale variation in prey abundance. Condor 95: 94-103.

Colwell, M. A. and Mathis, R. L. (2001) Seasonal variation in territory occupancy of nonbreeding Long-billed Curlews in intertidal habitats. Waterbirds 24: 208-216.

Connors, P. G., Meyers, J. P., Connors, S. W. and Pitelka, F. A. (1981) Interhabitat movements by Sanderlings in relation to foraging profitability and the tidal cycle. Auk 98: 49-64.

Dankers, N. and Zuidema, D. R. (1995) The role of the Mussel (Mytilus edulis L.) and mussel culture in the Dutch Wadden Sea. Estuaries 18: 71-80.

Dann, P. (1991) Feeding behavior and diet of Double-banded Plovers Charadrius bicinctus in Western Port, Victoria. Emu 91: 179-184. 
Evans, P. R. (1979) Adaptation shown by foraging shorebirds to cyclic variations in the activity and availability of their intertidal invertebrate prey. Pp. 357-366 in E. Nayloy and R. G. Hartnoll, eds. Cyclic phenomena in marine plants and animals. Oxford: Pergamon Press.

Everett, R. A., Ruiz, G. M. and Carlton, J. T. (1995) Effect of oyster mariculture on submerged aquatic vegetation: an experimental test in a Pacific Northwest estuary. Mar. Ecol. Prog. Ser.125: 205-217.

Godin, J. G. (1977) A Great Blue Heron preying on shiner perch in deep water. Can. Field-Nat. 91: 88-90.

Goss-Custard, J. D. (1970) Feeding dispersion in some overwintering wading birds. Pp. 3-35 in J. H. Crook, ed. Social behavior in birds and mammals. New York: Academic Press.

Goss-Custard, J. D. (1976) Variation in dispersion of Redshank Tringa totanus on their feeding grounds. Ibis 118: 257-263.

Goss-Custard, J. D. (1977) The ecology of the Wash. III. Density-related behaviour and the possible effects of a loss of feeding grounds on wading birds (Charadrii). J. Appl. Ecol. 14: 721-739.

Goss-Custard, J. D. (1980) Competition for food and interference among waders. Ardea 68: $31-52$.

Goss-Custard, J. D. (1984) Intake rates and food supply in migrating and wintering shorebirds. Pp. 233-270 in J. Burger and B. L. Olla, eds. Shorebirds: migration and foraging behavior. New York: Plenum Press.

Goss-Custard, J. D., Kay, D. G. and Blindell, R. M. (1977) The density of overwintering redshank, Tringa totanus (L.) and Curlew, Numenius arquata (L.), in relation to the density of their prey in south-east England. Estuar. Coast. Mar. Sci. 5: 497-510.

Grant, J. (1984) Sediment microtopography and shorebird foraging. Mar. Ecol. 19: 293-296.

Griffin, K. (1997) Eelgrass ecology and commercial oyster cultivation in Tillamook Bay, Oregon. Garibaldi, OR: Report to Tillamook Bay National Estuary Project.

Hall, S. J., Basford, D. J., Robertson, M. R., Raffaelli, D. G. and Tuck, I. (1991) Patterns of recolonisation and the importance of pit-digging by the crab Cancer pagurus in a subtidal sand habitat. Mar. Ecol. Prog. Ser. 72: 93-102.

Harrington, B. and Perry, E. (1995) Important shorebird staging sites meeting WHSRN criteria in the U.S. Washington, DC: United States Department of the Interior, Fish and Wildlife Service.

Hayman, P., Marchant, J. and Prater, T. (1986) Shorebirds: an identification guide. Boston, MA: Houghton Mifflin.

Heck, K. L., Able, K. W., Fahay, M. P. and Roman, C. T. (1989) Fishes and decopod crustaceans of Cape Cod eelgrass meadows: species composition, seasonal abundance patterns and comparison with unvegetated substrates. Estuaries 12: 59-65.

Heck, K. L., Able, K. W., Roman, C. T. and Fahay, M. P. (1995) Composition, abundance, biomass, and production of macrofauna in a New England estuary: comparisons among eelgrass meadows and other nursery habitats. Estuaries 18: 379-389.

Hicklin, P. W. and Smith, P. C. (1984) Selection of foraging sites and invertebrate prey by migrant Semipalmated Sandpipers, Calidris pusilla (Pallas), in Minas Basin, Bay of Fundy. Can. J. Zool. 62: 2201-2210.

Homziak, J., Fonseca, M. S. and Kenworthy, W. J. (1982) Macrobenthic community structure in a transplanted eelgrass (Zostera marina) meadow. Mar. Ecol. Prog. Ser. 9: 211-221.

Kalejta, B. and Hockey, P. A. R. (1991) Distribution, abundance and productivity of benthic invertebrates at the Berg River estuary, South Africa. Estuar. Coast. Shelf Sci. 33: 175-191.

Kaspar, H. F., Gillespie, P. A., Boyer, I. C. and MacKenzie, A. L. (1985) Effects of mussel aquaculture on the nitrogen cycle and benthic communities in Kenepuru Sound, Marlborough Sounds, New Zealand. Mar. Biol. 85: 127-136.

Keller, M. and Harris, S. W. (1966) The growth of eelgrass in relation to tidal depth. J. Wildl Manage. 30: 280-285. 
Kelly, J. P., Evens, J. G., Stallcup, R. W. and Wimpfheimer, D. (1996) Effects of aquaculture on habitat use by wintering shorebirds in Tomales Bay, California. Calif.Fish Game 82: 160-174.

Kelsey, M. G. and Hassall, M. (1989) Patch selection by dunlin on a heterogeneous mudflat. Ornis Scand. 20: 250-254.

Lewis, F. G., III and Stoner, A. W. (1983) Distribution of macrofauna within seagrass beds: an explanation for patterns of abundance. Bull. Mar. Sci. 33: 296-304.

Mathis, R. L., Colwell, M. A., Leeman, L. W. and Leeman, T. S. (in review) Spatial distributions of non-breeding Long-billed Curlews in intertidal habitats: scale-dependent patterns. Western Birds.

Mattson, J. and Linden, O. (1983) Benthic macrofauna succession under mussels, Mytilus edulis L. (Bivalvia), cultured on hanging long-lines. Sarsia 68: 97-102.

Meire, P. and Kuyken, E. (1984) Relationships between the distribution of waders and the intertidal benthic fauna of the Oosterschelde, Netherlands. Pp. 57-68 in P. R. Evans, J. D. Goss-Custard and W. G. Hale, eds. Coastal waders and wildfowl in winter. Cambridge, U.K.: Cambridge University Press.

Metcalfe, N. B. (1984a) The effects of habitat on the vigilance of shorebirds: is visibility important? Anim. Behav. 32: 981-985.

Metcalfe, N. B. (1984b) The effects of mixed-species flocking on the vigilance of shorebirds: who do they trust? Anim. Behav. 32: 986-993.

Moore, J. E. (2001b) Assessment of shorebird and wader use on Bird Island in northern Humboldt Bay, California: is bird distribution affected by the presence of a bat ray exclusion fence? Eureka, CA: Report to Coast Seafoods Company.

Moore, L. M. C. (2001a) Comparative use of longline oyster beds and adjacent tidal flats by shorebirds and waders on Humboldt Bay, California. Unpublished Master's thesis, Humboldt State University.

Myers, J. P., Williams, S. L. and Pitelka, F. A. (1980) An experimental analysis of prey availability for sanderlings (Aves: Scolopacidae) feeding on sandy beach crustaceans. Can. J. Zool. 58: 1564-1574.

Norkko, J., Bonsdorff, E. and Norkko, A. (2000) Drifting algal mats as an alternative habitat for benthic invertebrates: species specific responses to a transient resource. J. Exp. Mar. Biol. Ecol. 248: 79-104.

Perkins, E. J. and Abbott, O. J. (1972) Nutrient enrichment and sand flat fauna. Mar. Pollut. Bull. 3: 70-72.

Pienkowski, M. W. (1982) Diet and energy intake of Grey and Ringed Plovers, Pluvialis squatarola and Charadrius hiaticula, in the nonbreeding season. J. Zool. 197: 511-549.

Pienkowski, M. W. (1983) Changes in the foraging pattern of plovers in relation to environmental factors. Anim. Behav. 31: 244-264.

Puttick, G. M. (1984) Foraging and activity patterns in wintering shorebirds. Pp. 203-231 in J. Burger and B. L. Olla, eds. Behavior of marine animals. New York: Plenum Press.

Quammen, M. L. (1982) Influence of subtle substrate differences by shorebirds on intertidal mudflats. Mar. Biol. 71: 339-343.

Raffaelli, D. and Milne, H. (1987) An experimental investigation of the effects of shorebird and flatfish predation on estuarine environments. Estuar. Coast. Shelf Sci. 24: 1-13.

Reed, A., Ward, D. H., Derksen, D. V. and Sedinger, J. S. (1998) Brant (Branta bernicla). No. 337 in A. Poole and F. Gill, eds. The Birds of North America. Washington, DC: The Academy of Natural Sciences, Philadelphia, and the American Ornithologists' Union.

Selman, J. and Goss-Custard, J. D. (1988) Interference between foraging redshank Tringa totanus. Anim. Behav. 36: 1542-1544.

Shepherd, P. C. F. and Boates, J. S. (1999) Effects of a commercial baitworm harvest on Semipalmated sandpipers and their prey in the Bay of Fundy Hemispheric Shorebird Reserve. Conserv. Biol. 13: 347-356. 
Simenstad, C. A. and Fresh, K. L. (1995) Influence of intertidal aquaculture on benthic communities in Pacific Northwest estuaries: scales of disturbance. Estuaries 18: 43-70.

Soulsby, P. G., Lowthion, D. and Houston, M. (1982) Effects of macroalgal mats on the ecology of intertidal mudflats. Mar. Pollut. Bull. 13: 162-166.

Stenzel, L. E., Huber, H. R. and Page, G. W. (1976) Feeding behavior and diet of the Long-billed Curlew and Willet. Wilson Bull. 88: 314-332.

Stinson, C. H. (1977) The spatial distribution of wintering Black-bellied Plovers. Wilson Bull. 89: $470-472$.

Stinson, C. H. (1980) Flocking and predator avoidance: models of flocking and observations on the spatial distribution of foraging wintering shorebirds (Charadrii). Oikos 34: 35-43.

Stoner, A. W. (1980) The role of seagrass biomass in the organization of benthic macrofaunal assemblages. Bull. Mar. Sci. 30: 537-551.

Townshend, D. J., Dugan, P. J. and Pienkowski, M. W. (1984) The unsociable plover - use of intertidal areas by Grey Plovers. Pp. 140-159 in P. R. Evans, J. D. Goss-Custard and W. G. Hale, eds. Coastal waders and wildfowl in winter. Cambridge, U.K.: Cambridge University Press.

Turpie, J. K. (1995) Non-breeding territoriality: causes and consequences of seasonal and individual variation in Grey Plover Pluvialis squatarola behaviour. J. Anim. Ecol. 64: $429-438$.

Turpie, J. K. and Hockey, P. A. R. (1997) Adaptive radiation in the foraging behavior of Grey Plover Pluvialis squatarola and Whimbrel Numenius phaeopus. Ibis 139: 289-298.

United States Army Corps of Engineers (1997) Public Notice Number 22720N. Department of the Army, South Pacific Division, San Francisco District.

Velasquez, C. R. and Navarro, R. A. (1993) The influence of water depth and sediment type on the foraging behavior of Whimbrels. J. Field Ornithol. 64: 149-157.

Waddell, J. E. (1964) The effect of oyster culture on eelgrass (Zostera marina L.) growth. Unpublished Master's thesis, Humboldt State University.

Yates, M. G., Goss-Custard, J. D., McGrorty, S., Lakhani, K. H., dit Durell, S. A. E. le V., Clark, R. T., Rispin, W. E., Moy, I., Yates, T. J., Plant, R. A. and Frost, A. J. (1993) Sediment characteristics, invertebrate densities, and shorebird densities on the inner banks of the Wash. J. Appl. Ecol. 30: 599-614.

LINDA M. CONNOLLY ${ }^{1}$ and MARK A. COLWELL

Department of Wildlife, Humboldt State University, Arcata, CA 95521, U.S.A.

${ }^{1}$ Present address: California Department of Fish and Game, 18110 Henry Miller Ave, Los Banos, CA 93635, U.S.A. (e-mail: r4bio2@dfg.ca.gov)

Received 31 May 2004; revision accepted 5 January 2005. 